\title{
The Experience of the Infant Entering Refuge (Shelter) Setting with Their Mothers After Fleeing Family Violence
}

\author{
Wendy Bunston $^{1,2} \cdot$ Margarita Frederico $^{2} \cdot$ Mary Whiteside $^{2}$ \\ Accepted: 8 November 2020 / Published online: 26 November 2020 \\ (C) Springer Science+Business Media, LLC, part of Springer Nature 2020
}

\begin{abstract}
Almost nothing is known about how the infant may experience being in a women's Refuge (Shelter) setting with their mother after fleeing family violence, despite the high numbers of infants and young children in Refuges or Shelters. This research was concerned with exploring how the infant experienced refuge within a Refuge setting post family violence. Using a non-intrusive, ethically informed, 'infant led' approach, this research involved ten infants (aged 3 weeks to 16 months), ten mothers, and 13 staff in eight Refuges from three countries: Australia, Scotland and England. Data was collected through infant observation, interviews with mothers and then staff. Presented is a synthesis of a research methodology which was led by the infant, drew on concepts of 'inter-subjectivity' and used a constructivist grounded theory method. Infants were often lost from view within the Refuge setting. The mother, herself traumatised, was expected to be the refuge for her infant. Only the obviously distressed infant was assisted, and where available, from outside specialist workers. It was often too painful for the adults, both mothers and staff, to see or reflect on the infant's possible trauma. Significantly, in all cases the motivation for each mother to enter Refuge was ensuring their infant's safety. Concern for their infant or young child can be a powerful catalyst for women leaving a violent relationship. Refuges (Shelters) are in a unique position to respond to the infant in their own right whilst helping to heal and grow the infant/ mother relationship.
\end{abstract}

Keywords Infant led qualitative research · Refuges/shelters · Family violence $\cdot$ Intersubjective constructivist grounded theory · Infant observation $\cdot$ Infant mother relationship

\section{Introduction}

Infants and children residing in Refuges (or Shelters) often exceed the number of women. Infants under four make up the highest cohort of children entering crisis accommodation (AIHW 2012; Shinn 2010), however, have received little to no attention in the literature (Bunston 2016; Campo et al. 2014).

Wendy Bunston

W.Bunston@latrobe.edu.au

Margarita Frederico

M.Frederico@latrobe.edu.au

Mary Whiteside

M.Whiteside@latrobe.edu.au

1 wb Training \& Consultancy, La Trobe University, Bundoora, Victoria, Australia

2 School of Allied Health, Human Services and Health, La Trobe University, Bundoora, Australia
What occurs within Refuge (or Shelters) for the infant, particularly those aged 12 months and under, can only be inferred by exploring what 'related' research and literature has to offer. This pertains to specific therapeutic programs with individuals or groups of women and infants who reside in Refuge but attend outside services (Groves 2002; Lieberman and Van Horn 2004 2008) or interventions delivered in-house to enhance the relationship between the infant and mother (Bain 2014; Bunston and Glennen 2008; James and Newbury 2010; Keeshin et al. 2015). Absent from research is what may be the infant's experiences of their everyday life in crisis accommodation services and whether they find refuge in Refuge. ${ }^{1}$

This research sought to understand the subjective experience of the infant in Refuge and how the context of Refuge

\footnotetext{
${ }^{1}$ Refuge with a capital ' $R$ ' is used to designate a building or shelter, over refuge as a feeling state. The latter is achieved for the infant through the maintenance of, and ready access to a familiar person, most often their mother, in order to feel secure and protected in case of an emergency. Bowlby (1988) argued that this serves a biological purpose intrinsic to human development (see Bunston 2016, p: 25-26 for more information).
} 
provided a sense of refuge for the infant and their mother following fleeing family violence. Preverbal infants under 12 months and their mothers were the focus of this study. However, one infant aged 16 months was included following a miscommunication about their age. The purpose was to gather observational information directly from the infant, first and foremost; to then explore their experience in a Refuge setting. This was followed by semi structured interviews with their mothers, and then staff. All participants were recruited by Refuge staff once the staff themselves deemed the researcher trustworthy. The mothers then had a brief meeting with the researcher to decide if they would like to participate. Only one mother declined to be involved before her scheduled interview following a disagreement with the Refuge over an unrelated issue. Undertaken by the one researcher throughout, and after seeking fully informed consent, this research involved the collection of observational data, interviews, and meetings with research supervisors. It was recognised that meaning is made continuously and reciprocally though 'intersubjective' exchanges between people and occurs from the very beginning of life (Ammaniti and Gallese 2014). This was complemented further by utilising a 'constructivist grounded theory' approach in making transparent how these exchanges of meanings also emerged through the researcher actively engaging with and interpreting the data itself (Charmaz 2014).

Accessing a suitable number of Refuges for this research (all of which were medium to maximum security) was initially problematic and necessitated eventually following up leads across three separate countries. Getting access to the secret and appropriately, well-guarded world of the Refuge eventually came down to using existing contacts and networks the researcher had available to her. Furthermore, it was imperative to recognise the sensitivity of Refuge/Shelter settings and ensure the confidentiality of all research participants and all residents in the Refuge space. Infant observation was selected as the most unobtrusive and germane method for collecting data from the infant, followed by interviewing the infant's mother, then staff and key informants.

Existing Research with Children in Refuge Where studies regarding homelessness and crisis accommodation have directly involved children, the emphasis has largely been on measuring the impact of homelessness on their growth, development and functioning, with a tendency to rely on standardised quantitative measures over seeking their perspective (Huntington et al. 2008; Samuelson et al. 2012; Shinn et al. 2008). Even where there is a specific focus on children, research has relied solely on the accounts of their mothers (Lindsey 1998).

Research into the effects of family violence on children (including infants) has similarly focused on measuring impacts rather than inviting their participation (Levendosky et al. 2012, 2013). Often mothers alone are interviewed, removing the input of the very children such studies proport to explore (Buchanan 2011; Insetta et al. 2015; Mbilinyi et al. 2007). What research has unequivocally demonstrated is that infants are affected by trauma (Bosquet Enlow et al. 2012; Levendosky et al. 2013; Schechter and Willheim 2009). Even at this early stage, "violence witnessed as young as 2 months old is held vividly in non-declarative memory, and if untreated can be expressed in fragmented form throughout the child's life" (McIntosh 2002, p. 234).

Infants, Family Violence and Homelessness Although much has been written about the detrimental impacts of ongoing relational trauma on the developing infant (Corvo 2019; Gilbert et al. 2009; Schechter et al. 2019; Tailor and Letourneau 2012), there have been few attempts to explore the perspective of the traumatised infant, or recognise those infants most clearly 'at risk' and needing Refuge in times of crisis. These infants and mothers are not only impacted by family violence but homelessness and the challenges of navigating the crisis accommodation system. There is no discernible research about what occurs 'in-house' for infants who, with their mothers, enter into Refuge post family violence (David et al. 2012). High risk and transient populations such as these are often excluded from research as they are difficult to access, hard to engage and challenging to track (Booth 1999; Thompson and Phillips 2007).

\section{The infant's Perspective in Research}

Amidst our clamour to achieve scientific rigour, gold standard research and quantitative homogeny in our work with infants we may inadvertently dismiss discovering the perspective of the very little person we are most seeking to understand; particularly those most vulnerable and hidden away. Despite growing interest in infant mental health, formative brain development and the early years generally, there is surprisingly little research that seeks to include the perspective of the infant. Even research which directly concerns itself with the infant routinely fails to make space to consider what might be the subjective experience of the infant (Brooks et al. 2016; Buchanan 2011).

In studying the first cry of the newborn, Van Manen (2017) was interested in moving beyond a linear, physiological explanation which sees the first cry as manifesting their transition from the womb to extra-uterine life. Rather than simply a reflex, Van Manen (2017) states that in "watching a baby cry, we realize that a cry is effortful, expressive, and intentional", and it remains "unclear how this biological-physio-logical cry is sensually, consciously, or preconsciously engaged by the newborn infant." (p.1071). In seeking insight into the infant's experience, researchers and observers are served well by taking on a phenomenological perspective, adopting a position of "knowingly being speculative" (p.1070). The "newborn may 
experience the world in a vastly different way to the adult owing to differences in brain and body maturity" as the infant cannot use words to explain their experience, "if experience is even the correct word... And yet, understanding the meaning of the first cry is crucial to health science professionals who practice in the context of neonatal-perinatal medicine" (Van Manen 2017, p. 1070).

Inclusion At the very least, being able to speculate about what the infant might be experiencing gives gravitas to their right to be included within research which involves them. At the most, finding ways to purposefully include the infant's presence and perspective opens potential to include their voice in research about matters which directly affect them. By not making this space we risk "the elimination of an important category of knowledge, namely the knowledge of the child" (Schmidt Neven 2007, p. 202). Infants exposed to family violence are amongst those who are most vulnerable. The UN Charter on the Rights of the Child is unequivocal: children have the right to be protected and kept safe from violence (UN 1989). The UN Report on Violence against Children is also clear that they have the right for their experience of violence to be included in research. (Pinheiro 2006). The infant, by virtue of their developmental state are vulnerable, and "persons who are vulnerable are at greater risk of not being heard" (Hall Gueldner et al. 2012, pp. 125-126).

\section{Epistemology}

This research used an 'infant led' approach which actively enhances the depth of the infant's participation:

\section{Giving infant involvement and infant data the lead in research that includes them is a blatant and political decision; this is a deliberate demand to recognise the infant's right to be seen, thought about, engaged with and her or his experiences reflected on, and cogently inserted into any research where she or he is part of the landscape of the inquiry. (Bunston et al. 2020a, b, p.6).}

Deliberate decisions were made to commence with the infant as the first collection point for data and embedding the infants' data as the foundation upon which all subsequent analysis was built. This meant commencing with an observation of the infant before collecting any other data and ensuring this data was "analysed before any other and used as the foundation upon which any or all other data was thematically coded, and categories delineated (see Bunston et al. 2020a, b, p. 83). This was to guarantee that space was to be made to see, hear and consider the viewpoint of the infant. An 'intersubjective approach' (Ammaniti and Ferrari 2013; Beebe and Lachmann 1998), embedded within constructivist ground theory methodology (Charmaz 2014) informed the implementation of the study, holding the view of the infant as "having a mind and an intentional self from birth, who very early recognises his or her own body and feelings as different from those of others and who has capacity for empathy" (Thomson Salo 2007, p. 183). Context is everything in capturing the infant's world and this compelled the research to fit in with them, not the infant and their world to fit in with the researcher. Ultimately, the voice of the researcher interpreting and analysing the data will always win out over the infant and other participants. The efforts made to counter this invariable power disparity in research involving infants requires deliberate decision-making, with purposeful steps being taken to ensure that the infant and their experience remains at the forefront of such research. ${ }^{2}$

\section{Ethical Research with Vulnerable Infants and their Mothers} Not including infants in research which directly concerns them robs that research of creating space to speculate on what might be their experience. There are several data collection methods which can bring the infant sensitively into the landscape being explored. Filming infant interactions offers a powerful way to capture 'in time' what is happening for the infant, and sometimes in their own environment (Puckering et al. 2011). Again, in practice, this tends to be used to classify behaviours rather than directly exploring alternative possibilities through the rich raw data provided by the infant themselves.

Transparency and explicitness regarding all aspects of the research process is crucial in laying bare for the reader just how judgements are made, and analysis conducted. This includes making apparent the researcher's capacity to have an impact on, and be impacted by, what is observed (see Bunston 2016). University ethics approval for this research was gained, and each Refuge was asked if further amendments were required as appropriate to their settings. The decision to not film resulted from preliminary discussions with one Refuge, and deemed as an inappropriate method for collecting infant data in a setting which is often communal, where families have experienced intrusive and controlling surveillance at the hands of abusive partners, and where anonymity is imperative.

Infant Observation Adapting the discipline of infant observation into a research tool was selected as an appropriate data collection method for this setting (Datler et al. 2014; Rhode 2004; Rustin 1997). This process involved both recording meticulous notes immediately post observation and making prominent the experience of the infant through "seeking to access internal emotional states as well as the meanings of external behaviours...giving expression to the 'voices' (Elfer 2012, p. 225) of these infants. This approach acknowledged and encouraged an observation process where the observer

\footnotetext{
${ }^{2}$ See Bunston et al. (2020a, b) and Bunston (2016) for a fuller account of the methodology utilised in this research.
} 
"repeatedly allows him/herself to be affected by the experience" (Caron et al. 2012, p. 229). This method recognised that meaning is made through the interaction of what is seen and how it is seen and then understood by the observer (Bic 1964; Reddy and Trevarthen 2004; Winnicott 1968/1988). Reviewing the raw data (observation notes and interview transcripts) the data analysis process relied on regular reflective meetings involving two research supervisors and a 'critical friend', an expert in infant observation. This reflective space aligned with 'seminar groups' used in infant observation to present and explore the nuances of data collected (Bick 1964; Caron et al. 2012; Datler et al. 2014; Rustin 2009; Waddell 2013).

Intersubjectivity Recognition of interactional processes are critical to understanding the world of the infant (Ammaniti and Gallese 2014; Stern 1985/2003, 2010). Infants are totally dependent on and cannot exist without their caregiving world, physically or emotionally (Winnicott 1960). However, how we become ourselves is through relating to others. How we make sense of our own mental states and that of others is impacted by how well our earliest relational caregiving system tolerates rather than impinges on our development as an "independent being" (Fonagy et al. 2007, p. 302). Information is taken from the outside in, as infants organise their sensate experiences of caregiving responses, and from the inside out, as the infant matches and mixes these within their intimate relationships. Their experience of this interaction is then "finally reinternalized in the infant's (and the caregivers') internal world ... In other words, intersubjective interactions as observable behavior are modified by the intrapsychic representations of the protagonists, but the intrapsychic representations, too, are modified at the very same time by the actual intersubjective interactions" (Bürgin 2011, p. 111).

The individual is impacted by their own emotional states as well as the states of others, and interactively this happens together. It is acknowledged up front that this includes the presence of the researcher in observing, talking with, and thinking about the infant, carer and caregiving system, joining with and co-constructing the very system being studied.

'Intersubjective' Constructivist Grounded Theory Simply being present in a space impacts that space. Undertaking observations, conducting interviews, collecting data and the interpretation of the data itself moves through another layer of intersubjectivity (Crotty 1998; Medico and SantiagoDelefosse 2014). Such impacts are not only acknowledged but embraced by constructivist grounded theory and the emergent confluence of multiple social realities and perspectives. This theory honours 'theoretical usefulness' over 'meticulous accuracy' in order to build knowledge that can make a valuable contribution to practice (Charmaz 2014). Over and above other methodological approaches, constructivist grounded theory offers flexibility, rigour, and a focus on not what separates but what comes together, and how. The decision to be infant led gives the smallest voice an opportunity to be heard amongst other, more powerful voices, leading to new discoveries (Bryant and Charmaz 2007; Charmaz 2014).

\section{Implementation}

Participants The research involved 33 participants. Nine of the ten infants were under 12 months with the age range 3 weeks to 16 months; also involved were 10 mothers and 13 Refuge staff/key informants. Eight Refuges participated, three in Melbourne and two in remote Australia, one in London, England and two in Glasgow, Scotland: with 5 workers and 4 key informants from across the three countries. The data collected consisted of $18(1 \mathrm{~h})$ 'infant observation' sessions involving the 10 infants. One infant had been in Refuge previously, two were born in Refuge and over half had been in Refuge for less than 7 days, two less than a month and three between 3 and 12 months (see Bunston 2016, p:105). Of the six infants who recently entered Refuge, one was observed during admission and three others within 3 days of admission. The number of infant observations were determined by the availability of the mother, and the researcher.

Data Collection and Analysis The collection of data began with the infant in each of the dyads who participated in the study, using a method of infant observation informed by the Tavistock model (see Bick 1964; Waddell 2013). This captures dense, vivid and rich details of the infant/mother interaction and can also operate as a research tool which fits within a heuristic framework of knowledge generation (Rustin 1997, 2009). Following the infant observation mothers were interviewed (and audio recorded) using a set of semistructured questions. Staff and key informants (experts in the Refuge work) were then interviewed using similar questions.

The analysis commenced with the infant data, followed by their mother's interview data. This moved sequentially through the analysis of each dyad (from the first infant/ mother through to the last infant/mother), with themes emerging for initial coding. A re-analysis of the initial emergent themes occurred through revisiting all the infants' data collectively, and next, moving collectively to the mothers' data. Finally, the Refuge staff and key informant data was analysed. A fourth layer was also acknowledged, that of the researcher and, less cogent but still of influence, the supervision group of the researcher. Consisting of the researcher, two supervisors and an 'infant observation trained' critical friend, this provided an ongoing reflective space, committed to continuous and rigorous interaction with the infant data and with specific deliberation given to how this was analysed and coded. 


\section{Findings}

\section{Research Question: What was experienced as refuge for the infant?}

Answer: Staying in proximity to their primary relationship figure, most often their mother, through whatever means possible. The data clearly demonstrated that refuge for an infant is not a building but a relationship. They did not seek out a place, but a person. Furthermore, the research suggested a delineation between the physical (being held in the arms of) and the emotional (being held in the mind of) for many of these infants, resulting in some infants settling for whatever they could get. The protection they largely sought, and the protection they were given, predominantly came from their mother. When the infant found refuge in their mother, often their behaviour and emotional state aligned with what they anticipated their mothers needed from them so as not to risk severing that connection. Some infants were able to find a reciprocity in their relationships with their mother where they not only found refuge but safety, and a mutuality of coregulation and meaning making. These infants demonstrated that they could express their feeling states, felt seen, and were responded to as together they discovered how best to manage these states.

Visit One (Infant One, 3 months old)

The infant finding both refuge and the experience of

feeling safe within that Refuge was observed in both of my observations with this infant. She was able to ask for, and take comfort from, her mother. In the first observation I recorded that "the mother was very responsive to her infant, returning her gaze, smiling at her, talking to her, and the infant was chatting quite a lot, so lots of vocalising. Again the mother was asking her questions and having a conversation with her and telling her "what a lovely girl she was" and "what an interesting girl she was" and how "she had lots that she wanted to say" and the infant drank this all in as she looked into her mother's face.

\section{Visit Two (the following day)}

During the second observation with this dyad, a minor miss-cue occurred between the couple. The mother misread the meaning of the infant's frustration at not being able to reach a hanging mobile toy as she "did not seem to see this and responded by taking her out of the rocker altogether, which seemed to make the infant even more upset". This dissonance was minor, and the infant felt free to protest and also prepared to attempt her mother's solutions, which included trying to feed her and then rocking her. However, the two were able to work through this and return to finding an enjoyable equilibrium... The mother went and got two storybooks from the bookcase in the corner of the room and sat down next to the infant and read her the books. The first one was the story of "the wheels on the bus". The infant looked up at the book, which was open, and the mother proceeded to read the book to her and sang the song. "the wheels on the bus go round and round"... The infant remained very engaged in the process, watching her mother's face all the while.

Not all infants, however, found refuge or safety in their relationship with their mother, with some exhibiting a 'pseudoindependence' suggestive of a greater reliance on themselves than on their mother (Pretorius 2004), whilst others appeared to have learnt to 'shut down' when with their mother:

When I arrived, the mother had been feeding Infant Eight who was 7 months old. He was refusing to eat and making a mess of his food. She got increasingly frustrated with him ... At one point she became quite sharp with him and said, "Enough!" which gave me a bit of a fright when she said it, so I imagine gave her baby a little bit of a fright. After this confrontational interchange the mother removed herself to the kitchen in the room next door, leaving the infant in his walker, and alone with me. When his mother left the room, the infant moved himself in his walker towards the television but got lodged between the wall and television cabinet. This meant he had to twist his neck back awkwardly around to see the television and proceeded to do so more than a dozen times over a ten-minute period, turning back when he could no longer bear the discomfort and then twisting around again. Finally, he let out an angry cry. Throughout this whole time, I sat in front of him. Not once did he make any overture towards me for help. Did he not expect any help? (Bunston 2016).

Bowlby (1988) suggested that for the infant who is "in extremity and with no one else available, even a kindly stranger may be approached" (p.27). This infant, however, appeared to have learnt to rely on himself. Another infant exhibited the changes of emotional states that can occur over time. This involved the infant presenting in a dissociative state in the first observation during their admission to the Refuge and after a gruelling day at court, to a month later with the infant presenting as significantly more settled, albeit still exhibiting dissociative features.

Visit One (Infant Two - 4 months old)

As I walked with his mother to the nearby shops, pushing his stroller whilst his mother had a cigarette, I could see the infant's little face when we would pass under each streetlight. And it was a pained little face. He had a little frown and he was looking intently at me 
and I think trying to figure out who I was and where he was ... it was almost like I could see it had been an horrific day. He was exhausted and he was just looking at me intently and frowning. There was no friendly curious engagement, it was like, just frozen, and I felt very teary, and feel teary recalling it and writing about it.

\section{Visit Three (One month later)}

When I arrived at the Refuge, I was shown in by staff who then left me alone with Infant Two, who was lying on a rug in the back-lounge room. He seemed to be entertaining himself playing with a hanging mobile and together we remained waiting for his mother, who was outside having a cigarette. I spoke to the infant and he reciprocated. When his mother returned, she greeted me and her infant warmly, then sat on the couch next to his rug. While this mother interacted verbally with her infant, she mainly directed her conversation towards me. The infant remained on the rug for some further 30 minutes after his mother sat down, moving between entertaining himself and then staring off into space, but eventually began fussing and crying...I started to push at the bottom of his feet and he seemed to enjoy pushing against my hands so that stopped him crying and he seemed to enjoy my involvement and then Mum came back with the bottle. She picked baby up and gave him a bit of a cuddle and put the bottle to his lips but he didn't take the milk. She did this a few times and he let her know fairly clearly that he didn't want the bottle, so she said to him, "Maybe you need to have your nappy changed," so we went upstairs ... During this observation session, and as was evident in the previous two, this infant did not have a great deal of physical contact with his mother. When he did, it was generally to serve a function, eg. she would give him a drink or something to eat or change his nappy or clothes. I noted in this third session that: "a couple of times I wondered where he was disappearing to. I could see that he got that stare"

Research Question: How are the needs of the infant met when entering Refuge in order to make them feel safe?

Answer: The needs of the infant are the responsibility of the mother as she is 'refuge for her infant', with the mother being responsible for meeting the developmental needs of her infant while the Refuge supports her Just as the mother is expected to provide refuge for the infant, so too are they expected to meet their infant's developmental needs. This is not without some support from the Refuge through key women's and family support workers or, as in a larger Refuge, through services such as parenting classes. The prevailing view, however, was that the infant is an extension of the mother. This sentiment was mentioned repeatedly by Staff and Key Informants across all Refuges. As summed up by these two comments taken from two different countries:

"Shelter is really here to cater for the women, children are more seen as an extension of the mothers"; "Babies wouldn't be ... the first consideration. Their safety is, but then ... it's the mum".

This was a view held not only by the staff, but by the mothers themselves:

(Mother One), "a baby only needs her mother". (Mother Two), the key to the infant receiving refuge came "down to us mums", as the infant is "my responsibility" (Mother Three), "they just live with us, no stress, no panic, nothing" (Mother Six), as "his mind is on me".

It was expected that by meeting the needs of the mother, the needs of the infant were also met. Direct practical support, shelter and equipment attended to the infant's physical necessities. However, the developmental needs of an infant are as intrinsically emotional as they are physical and nutritional.

Research Question: How are the infant/mother attended to in order to bring the infant into an emotionally regulated and healthy state?

Answer: The infant is attended to by the mother while the Refuge attends to the mother through providing her with shelter, food, clothing, goods and support when needed. The mother is expected to emotionally manage the infant. If she is unable to do this, expert help from outside the Refuge is called upon (if available), or child protection involvement may be required Attention to the emotional states of the infant requires an awareness within the mother of her own emotional and mental state without impinging on that of the infant's own subjectivity and developing sense of self. This means being able to think about her infant as separate from herself. Fonagy et al. (2007) contends that "the awareness of the infant in turn reduces the frequency of behaviours that would undermine the infant's natural progression towards evolving its own sense of mental self through the dialectic of her interactions with the mother" (p.302). It is this inter-subjective process which provides security, above all else.

The mother's ability to think about her own needs let alone those of her infant, appears to be severely compromised by the cascade of events leading up to their admission into Refuge. Whilst Refuge offered the relief of accommodation, this "was my salvation in that I don't know where to go but now that I know there is some places like this so it's really good" (Mother Three); a sentiment echoed by (Mother Seven), offering her much more than "just a room ... you are no stranger, you think you belong here". There remained, however, an 
underlying insecurity which made them vulnerable to their environment and the kind of refuge being provided by the Refuge:

(Mother One) felt that little effort had been made to ask her what she wanted, or to explain what options might be available in terms of secure housing, "because they were quite blunt that that's not what they were there to help for". (Mother Nine) was much more explicit, and repeatedly expressed feeling abandoned by the Refuge throughout the interview: "To me it's felt like they have basically put me in the property and left basically, not dumped me, but it feels like they dumped me and kind of forgotten until they need to meet their quota, if you know what I mean". (Mother Eight) and her infant had been in Refuge for six months. They were currently alone in the share house. The children's worker - "she stays like about an hour" - had not been to visit in over two weeks: "Normally she comes every week, so I think she is busy or something".

Research undertaken specifically with mothers who have family violence-related PTSD have been assessed as demonstrating limited capacity to read the emotional cues of their infant (HuthBocks et al. 2004; Schechter et al. 2012). Should the Refuge itself not possess the capacity to reflect on the mind of the moth$\mathrm{er}$, and therefore her capacity to reflect on the mind of the infant, it may be that neither infant not mother are having their emotional or developmental needs met adequately in the context of recovery from violence and the transition to motherhood.

Research Question: How does entry into Refuge impact the infant/mother relationship?

Answer: Leaving the violent ex-partner and entering the protected space of Refuge serves to intensify the infant/mother relationship, magnifying the perceived responsibility of the mother for her infant. Every mother is this study indicated that their motivation for leaving their violent relationship was directly related to the concern they held for the wellbeing of their infant. However, in some respects, the process of entering Refuge for the sake of their infant appeared to heighten already existing fragilities within the mother/infant relationship, and perhaps in unanticipated ways:

There almost seemed be a stronger relationship between baby Seven and the worker ... she (the mother's key worker) was about to leave the room and the baby started crying and I noticed that the mother pushed the baby out towards the worker saying, "Take her. You can have her, you can keep her." And the worker did end up taking the baby, saying, "I'll hold her".

Whilst every mother in this study ultimately chose their infant over their partner, privileging the protection of their infant over their relationship with their violent partner, their partner's absence left something of a void, which their relationship with her baby now somewhat filled:

(Mother Three) "it is really sad to leave my home but now I have the baby and I just look at the baby and that helps me to feel better". (Mother Seven) "so yes, she give me this, and hope ... (Looking at baby) she put other goals in my life ... I was empty so she is filling up where I was empty".

There was an unanticipated sense of loss in some cases. Most of these mothers had been in relatively lengthy relationships before the birth of their infant. Given the complexity of intimate relationships and the increased complexity when violence is thrown into the mix, some elements of these women's relationships may nevertheless have felt positive and their partner's absence felt. There may have been little chance for infants to compete with the other people and stressors preoccupying their mother's minds. One mother who had come into the Refuge pregnant held out hope that the infant's birth might change the father, as he may "see my baby and he will look at himself and get treatment for himself to get together and change to improve himself" (Mother Three).

Should the mother or infant want to express any positive or conflicted feelings regarding the father, this may be difficult in a culture within Refuge which appears to omit references to fathers and men in general. "It was as though the fathers of these infants had completely vanished. They were obviously not present in the Refuge, nor having access. They were spoken of little, and when they were it was generally not complimentary and their connection to the infant had been diminished" (Bunston 2016, p:178). Whether to comply with a culture within women's Refuge that appeared to omit the father's potential relationship with the infant, as well as the mother's, this served to perhaps push the mothers, and even the infants feelings about their father underground. Leaving a violent partner does not necessarily guarantee a better sense of wellbeing or quality of life for all women (Bell et al. 2007; Davies 2008). Neither does this remove a mother's, or even an infant's preoccupation with the loss of the relationship they have formed with their father (Jones and Bunston 2012) or other significant others from whom they are now removed. The absence of the father and the way in which he is spoken about or not spoken about has implications, both positive and negative, for infant development and future relationships (Featherstone and Fraser 2012; Thiara and Humphreys 2015).

(Mother Six) noticed some mothers' hatred for their partners spilling over to their sons: "I think it's about what happened before she came here to Refuge ... if she have a son I think she hate him because he is man". When it came to her own daughter, however, she felt 
there would be no impact in growing up without her father, diminishing his relevance in her daughter's life or any possibility that she could miss him because "she doesn't remember". (Mother Two) immediately corrected a question I asked about her partner (the infant's father), replying firmly, "Ex-partner!" Some mothers suggested that the infant would not miss him, "because he is kind of working every day, 9 am till really late" (Mother Seven). Another suggested, (Mother Six) "She was happy when he is going to work" and (Mother Nine), "he didn't really get to spend much time with her so there really wasn't much of a bond at that point".

The mothers' experience of the Refuge itself appeared to also impact how they felt about their relationship with their infant. Some mothers felt that coming into Refuge removed the distress they had previously felt when living with a violent partner. The less stressed they were, the better mother they could be.

(Mother Six, when asked if her infant daughter was aware of her surroundings stated: "She know that she is here with me, and that's it". Similarly, (Mother Eight) announced: "I'm not letting anyone take care of my child. I'm going to take care of my child myself"

Again, this reinforced the notion of the baby as an extension of mother as 'the baby feels what I feel'. Their happiness would be automatically transferred to and shared by the infant. Where a mother was not satisfied with the Refuge, she could attribute difficulties her infant appeared to be having to the inadequacies of the Refuge, rather than to any struggles she may be finding in her mothering role. The infant themselves, again, seemed to get lost in this process.

Research Question: How does the infant experience safety ('refuge') in a Refuge environment?

Answer: When being seen, thought about, acknowledged, enjoyed and responded to for who they were, 'in and of themselves', the infant appeared to experience a feeling of safety in their interactions to the extent that they were able to relax ('let go'). This included being able to respond in-kind, and enjoy being with their mother, and sometimes staff as well, within the Refuge environment Within the context of a Refuge environment, the manifestation of 'experiencing safety' seemed to be when the infant could actually 'let go', confident in both feeling physically held and experiencing the safety that comes with being fully seen and enjoyed.

Visit One

Infant Seven (4 months) and her mother had been in the Refuge only three days. Attending their first formal large house meeting another woman picked up Infant Seven out of her stroller, chatted to her, then passed her along to the next woman sitting on the couch. The infant was passed to the next before eventually being handed back to her mother. Infant Seven "had a serious little face, I didn't see her smile, looking at others, but not a lot of smiles". When she reached her mother: "she just sat on her mum's knee, with her back against her mum's chest, looking out towards everyone else but no gesturing, no chatting or talking, just observing, basically".

\section{Visit Two}

When I arrived Mother Seven was cooking in her selfcontained unit, and all the while chatting away to her daughter. When she finished, she sat down on the floor next to Infant Seven. The mother was fully engaging with her baby - "yes my love, yes", talking to her baby who was responding and vocalising. "Yes, "oh my goodness, is that what happened when you were sleeping, all that stuff? I can't believe it". The mother was laughing and speaking back to infant about what she thought her infant was telling her.

Whilst 'finding refuge' generally appeared to involve being in proximity to their mother, this did not necessarily result in them feeling safe. Being really 'seen', and thus feeling safe, appeared to involve being thought about and responded to in a manner consistent with helping them to manage their physiological states, and in a manner congruent with what they were communicating. This is different to being 'looked at', as Beebe et al. (2011) suggests a situation which, for the anxious mother, can involve "vigilant visual monitoring, without empathic emotional response, (which) suggests that mothers may be 'looking through' the infants' faces, as if the infant is not 'seen' or 'experienced"' (p. 194).

Visit Two (Infant Six - 11 months old)

When I arrived, the infant was in her cot, awake, alert, playing with her toys and looking from me to her mother... Her mother interacted with her at different times, gently laughing at things that she did and seeming to enjoy her. The infant was chatting away, making a 'doo' 'doo' noise and quite industrious in her play and chatter within the cot. In all, she remained there very patiently for over twenty minutes with the first, very short hint of protest at about 16 minutes, then back to play, a round of very intense chatting just on twenty minutes, then at 21.30 minutes beginning to cry and this becoming increasingly loud. It wasn't until the little girl started to cry that she was pulled out of the cot. She gave a very sudden cry and then Mum picked her up and she stopped crying very quickly and I said, "Was that her cry to get out of the cot?" and she said, "Yes" and she 
sat the infant on her lap and told her to shh; she did, then mother placed her on the floor and she was crawling around the unit, very vocal, entertaining herself again very patiently.

Research Question: What knowledge do both staff and mothers have in relation to the needs of infants entering Refuge?

Answer: Cultural, community and familial beliefs, as well as inter-generational relationship patterns, inform mothers' knowledge about infants and even the knowledge of the staff, rather than looking to the infants themselves On the surface, it would appear there was little difference in how staff viewed the needs of the infant who requires the protection of Refuge accommodation in order to escape violence, and the infant who does not require such protection. That is, there was no tangible perception that the infants themselves might be needing their own specific support to recover from the impacts of living with family violence. However, a practice of 'calling in the experts' effectively enabled staff to keep themselves distant from the infant, emotionally and psychologically:

\section{Interview with a Key Informant \\ "It's something I don't go to because I just think that that's such a huge subject about babies and violence. I admit that I put it over there. It's hard enough doing what we're doing ... and then trying to work with the women as well ... let alone everybody else".}

When staff did reveal any sort of emotional attachment they had formed with an infant, it was acknowledged almost surreptitiously, and quickly dismissed. The staff were either not actively engaged in providing any direct caregiving to the infant or minimised how much of this they did, as such involvement was not really in their job description. This responsibility was seen to belong, in the first instance, to the mother, and in the second to the outside expert:

Two Key Informants suggested simply 'calling in the midwives' as they "come into our Refuge on a regular basis, so they would know that there was a baby of under one or a mother who was pregnant in the Refuge." Another Key Informant stated, "I think if the baby is distressed it would be an issue for the visiting health worker."

Some Refuges had no-one else they could call in. They only had themselves and, because they saw working with the infant as such specialist work, they noted that:

"The babies are an absolute afterthought ... we're not taught or trained in anywhere that I know of to treat the baby as a separate entity that could be damaged in any way by what it's just been through".

The refuge workers appeared to assume that through meeting the needs of the mothers; they were also meeting the needs of the infant. This assumption was not expressed through an inattention to the physical needs of the infant, but rather through the notion that the infant is not affected by the events that happen around them, even when there is evidence to the contrary. This supported a belief that should the infant be affected, they will not be likely to remember the events as they were too young, did not know what was happening to them and do not possess the capacity to talk about these things:

(Mother 11) "I don't know what they could do for my baby". She felt that the Refuge might be able to offer something to "the other kids that (are) older who can communicate if they're scared", but there was little the Refuge could do for an infant, "because they're babies, they can't tell us how they feel". (Mother 2) lamented directly to her son, "If only I could read your mind".

The notion that the infant may have their own reactions, trauma and feeling states and that they do in fact possess physiological memories of trauma (Van der Kolk 2014) was largely foreign to the mothers. Even when a children's worker was allocated to an infant, the mother felt the best they could do was 'just stay and we chat, that's all because he's too young and there's nothing he can really do" (Mother 8). The mothers appeared to consider that refuge for their infant occurs through them, and if they have their needs met, they can, in turn, meet the needs of their infant. This suggested that the 'mother knows best' what their infant needs.

\section{Discussion}

Concern for the infant was the motivating factor for all ten mothers to leave their violent partner, a finding consistent with other recent studies involving children (Rasool 2015; Secco et al. 2016). This may speak to the growing awareness of the negative impacts of violence on children, the rights of mothers and children to be free from violence, and an increase in service provision and supports than has been captured in earlier studies examining reasons for leaving (Bell et al. 2007; Meyer 2012).

However, this research also found that leaving a violent relationship and entering a Refuge did not guarantee that the traumatised infant and their mother would find refuge in Refuge. The provision of crisis accommodation may ameliorate the immediate physical threats to the mother and infant, but Refuge staff, though highly committed and compassionate were often ill-equipped, or inadequately supported, to address 
the lingering and complex psychological impacts on both. Additionally, the difficulty in seeing the infant as entitled to be equally thought about and responded is not inconsistent with society's generally 'adult-centric' approaches to health and welfare service delivery (Bunston 2016; McIntosh 2002, 2003; Thomson Salo and Campbell 2007). Furthermore, within the setting of Women's Refuges, the impetus to place more emphasis on empowering the mother may be derived from a culture which ensures that infants and children do compete with nor undermine the support needed for their mothers (Davies and Krane 2006; Krane and Davies 2002, 2007; Peled and Dekel 2010).

Staff not seeing the infant as individually affected by the experience of the violence, and/or leaving the infant emotionally unattended to, and completely expecting this to be provided by their mother once in Refuge, risked adding to the emotional deterioration of the infant. This may also have risked increasing compassion fatigue in some staff and triggering of their own personal histories (Taylor et al. 2019).

Unfortunately, infancy is developmentally the most vulnerable of any of the ages within childhood. Infants are also the most likely to be present during violent incidences and are the highest cohort to accompany their mothers into Refuge yet are the least likely to be seen, or provided with their own service response (AIHW 2012; Lieberman et al. 2011; Shinn 2010). This also reflects the way in which society and the media generally has medicalised infancy (Bunston 2016; Clarke 2015) reducing the confidence of generalist workers to think about or directly respond to infants, and adding to infants being lost from view. In particular, the expectation that the mother alone will be the refuge for the infant is unrealistic in the face of the mother's own extensive past and present trauma. While such practices continue, we will do little to interrupt the inter-generational transmission of violence. Refuges are imperative for mothers and their infants and children most at risk. They are a vital, physically safe holding space which is enhanced by the relational opportunities offered when they are adequately staffed and appropriately resourced. There is evidence of some valuable but largely intermittent work undertaken directly with infants in Refuge (Bain 2014; Bunston and Glennen 2008; Bunston and Sketchley 2012; Keeshin et al. 2015).

The inhibitors to seeing the infant as capable of being engaged with directly and emotionally was connected to a belief that it was the role of the Refuge to support the mother while she supported the infant. Both mothers and Refuge staff minimised the impact of the family violence experienced by the infant. In part, this was because they could not conceive of the infant as having a memory or relatable response to what was happening to them (Schechter and Willheim 2009). This was perhaps as a defence for both mothers and staff from feeling overwhelmed. The staffing group themselves, not unlike many of the mothers, were already carrying an enormous load, and certainly did not lack compassion, exhibiting an immense commitment to the mothers; but lacked access to adequate levels of funding, training, support and ready access to outside services. The introduction of regular reflective group supervision sessions for all staff working with infants and children in complex settings, even as little as on a monthly basis, has been demonstrated to enormously enhance the capacity of staff to hold, hear and keep in mind the infant and the child/mother relationship (Brinamen et al. 2012; Bunston and Sketchley 2012; O'Sullivan 2019).

The significance of fathers, and to some degree men in general, was also reduced and/or rendered unimportant. In part this was because specific questions regarding fathers was not canvassed in the research, but this alone does not explain the resounding silence about fathers unless in the negative. This opened the potential to leave the immature infant with little means by which to make sense of where and how their father, and men generally, featured in their lives. Worryingly, this then has implications for how the infant may then internalise, process and make sense of this vital element of their birth, early life story and emerging sense of self (Jones and Bunston 2012).

Finally, the necessarily secure and guarded nature of Refuge/Crisis Accommodation and Shelter settings impeded ready access to conducting research within this space. The need to reach out beyond one particular region, state, and even country both enriched this research and limited it. Whilst the numbers were too small to offer any extensive, nuanced, comparative findings between how infants experience Refuge across three different countries, what emerged as the most glaring difference was the lack of options, supports and length of stay being offered to infants and their mothers who needed Refuge in truly remote areas.

\section{Limitations}

This research was dependent on the researcher's interpretation of the inter-subjective space and was achieved through what was seen and felt through observational engagement with them. There was no pretext that this research was 'objective', as its purpose was to 'illuminate' rather than 'measure' (Charmaz 2014; Crott, 1998; Medico and SantiagoDelefosse 2014). To have sought to measure that which is subjective would have been contrary to what this research hoped to uncover and preserve: the 'phenomenon of interactions' (Silverman 2013). The observational data could not do justice to the complexity of the stories associated with the mothers who came into the Refuge setting, nor adequately capture the depth of feeling associated with how very distressing this work can be for Refuge staff.

What the methodology strived to capture were the relational behaviours of the infants, and to make meaning of these 
without the level of intrusion or inflexibility encountered in some of the more traditional methods used to undertake research with infants. The brevity of contact with each infant, mother and Refuge offered only a snapshot rather than a sequential sense of the infants' experience to any large degree, and the number of participants overall was small. To extrapolate extensively from this under-researched area using this small cohort of participants would be a mistake and was not the intended purpose. The lack of research regarding the infant in the setting of Refuge, even in the increasingly expansive arena of infant mental health, is indicative of the extent to which this environment in which so many infants are accommodated tends to be overlooked. This study offers a starting point for others to follow.

\section{Conclusion}

Infancy is the most rapid developmental and formative period in life. The traumatised infant does not have the time to wait for assistance whilst their mother recovers from what has been significant, and often accumulative relational abuse. Furthermore, the sooner the infant is responded to, their subjective experiences acknowledged and tended to, the sooner will come opportunities to capitalise on the relational hope the mother carries for her infant and herself. These mothers largely accessed Refuge in order to create a different future. Funding, training and supporting Crisis Accommodation Refuge and Shelter workers in how to directly work with traumatised infants in tandem with their mothers offers the family violence sector a unique opportunity to provide truly early intervention, and to capitalise on the hope we all carry for building a future for children and women which is free from relational violence.

Acknowledgements We are indebted to our "critical friend" in this research, Dr. Julie Stone.

\section{Compliance with Ethical Standards}

Conflict of Interest None to be declared.

\section{References}

AIHW. (2012). A Picture of Australia's Children 2012 (1742493572). Retrieved from Canberra:

Ammaniti, M., \& Ferrari, P. (2013). Vitality affects in Daniel Stern's thinking-A psychological and neurobiological perspective. Infant Mental Health Journal, 34(5), 367-375. https://doi.org/10.1002/ imhj.21405.

Ammaniti, M., \& Gallese, V. (2014). The birth of Intersubjectivity: Psychodynamics, neurobiology, and the self. USA: WW Norton \& Company.
Bain, K. (2014). "New beginnings" in south African shelters for the homeless: Piloting of a group psychotherapy intervention for highrisk mother-infant dyads. Infant Mental Health Journal, 35, 1-12. https://doi.org/10.1002/imhj.21457.

Beebe, B., \& Lachmann, F. M. (1998). Co-constructing inner and relational processes: Self-and mutual regulation in infant research and adult treatment. Psychoanalytic Psychology, 15(4), 480-516.

Beebe, B., Steele, M., Jaffe, J., Buck, K. A., Chen, H., Cohen, P., Kaitz, M., Markese, S., Andrews, H., Margolis, A., \& Feldstein, S. (2011). Maternal anxiety symptoms and mother-infant self- and interactive contingency. Infant Mental Health Journal, 32(2), 174-206. https:// doi.org/10.1002/imhj.20274.

Bell, M. E., Goodman, L. A., \& Dutton, M. (2007). The dynamics of staying and leaving: Implications for battered women's emotional well-being and experiences of violence at the end of a year. Journal of Family Violence, 22(6), 413-428. https://doi.org/10.1007/ s10896-007-9096-9.

Bick, E. (1964). Notes on infant observation in psycho-analytic training. The International Journal of Psycho-Analysis, 45, 558-566.

Booth, S. (1999). Researching health and homelessness: Methodological challenges for researchers working with a vulnerable, hard to reach, transient population. Australian Journal of Primary Health, 5(3), 76-81. https://doi.org/10.1071/PY99037.

Bosquet Enlow, M., Egeland, B., Blood, E. A., Wright, R. O., \& Wright, R. J. (2012). Interpersonal trauma exposure and cognitive development in children to age 8 years: A longitudinal study. Journal of Epidemiology and Community Health, 66(11), 1005-1010. https:// doi.org/10.1136/jech-2011-200727.

Bowlby, J. (1988). A Secure Base: Clinical applications of attachment theory. London: Routledge.

Brinamen, C. F., Taranta, A. N., \& Johnston, K. (2012). Expanding early childhood mental health consultation to new venues: Serving infants and young children in domestic violence and homeless shelters. Infant Mental Health Journal, 33(3), 283-293. https://doi.org/10. 1002/imhj.21338.

Brooks, J. L., Holdtich-Davis, D., Docherty, S. L., \& Theodorou, C. S. (2016). Birthing and parenting a premature infant in a cultural context. Qualitative Health Research, 26(3), 387-398. https://doi.org/ 10.1177/1049732315573205.

Bryant, A., \& Charmaz, K. (2007). Grounded theory research: Methods and practices. In A. Bryant \& K. Charmaz (Eds.), The sage handbook of grounded theory (pp. 1-28). London: Sage.

Buchanan, F. (2011). The effects of domestic violence on the relationship between women and their babies: Beyond attachment theory. $(\mathrm{PhD})$, Flinders University, Unpublished.

Bunston, W. (2016). How Refuge provides 'refuge' to Infants: Exploring how 'refuge' is provided to infants entering crisis accommodation with their mothers after fleeing family violence. ( $\mathrm{PhD}$ Thesis), $\mathrm{La}$ Trobe University, Melbourne. Retrieved from http://hdl.handle.net/ 1959.9/559171

Bunston, W., \& Glennen, K. (2008). BuBs' on board: Family violence and mother/infant work in women's shelters. Parity, 21(8), 27-31.

Bunston, W., \& Sketchley, R. (2012). Refuge for babies in crisis. Retrieved from Melbourne, Australia: https:/www.dvrcv.org.au/ sites/thelookout.sites.go1.com.au/files/Refuge $\% 20$ for $\% 20$ Babies $\%$ 20Manual\%20FinalWEB.pdf

Bunston, W., Frederico, M., \& Whiteside, M. (2020a). Infant-led research: Privileging space to see, hear, and consider the subjective experience of the infant. Australian Social Work, 73(1), 77-88. https://doi.org/10.1080/0312407X.2019.1676457.

Bunston, W., Frederico, M., \& Whiteside, M. (2020b). Infant led research: Privileging space to see, hear and consider the subjective experience of the infant. Australian Social Work, (InPress). https:// doi.org/10.1080/0312407X.2019.1676457.

Bürgin, D. (2011). From outside to inside to outside: Comments on intrapsychic representations and interpersonal interactions. Infant 
Mental Health Journal, 32(1), 95-114. https://doi.org/10.1002/ imhj.20285.

Campo, M., Kaspiew, R., Moore, S., \& Tayton, S. (2014). Children Affected by Domestic and Family Violence: A review of domestic and family violence prevention, early intervention and response services. Retrieved from Australia: https://www.women.nsw.gov. au/_data/assets/file/0014/300623/PDF-6_Final_Report_Children_ affected.pdf

Caron, N., Sobreira Lopes, R., Steibel, D., \& Schneider Donelli, T. (2012). Writing as a challenge in the observer's journey through the Bick method of infant observation. Infant Observation, 15(3), 221-230. https://doi.org/10.1080/13698036.2012.726519.

Charmaz, K. (2014). Constructing grounded theory (2nd ed.). London: Sage Publications Ltd.

Clarke, J. N. (2015). Advice to mothers about managing children's behaviours in Canada's premier woman's magazine: A comparison of 1945-1956 with 1990-2010. Child \& Family Social Work, 20(3), 310-321. https://doi.org/10.1111/cfs.12079.

Corvo, K. (2019). Early-life risk for domestic violence perpetration: Implications for practice and policy. Infant Mental Health Journal, 40(1), 152-164. https://doi.org/10.1002/imhj.21762.

Crotty, M. (1998). The foundations of social research: Meaning and perspective in the research process. Australia: Allen \& Unwin.

Datler, W., Datler, M., Hover-Reisner, N., \& Trunkenpolz, K. (2014). Observation according to the Tavistock model as a research tool: Remarks on methodology, education and the training of researchers. Infant Observation, 17(3), 195-214. https://doi.org/10.1080/ 13698036.2014.977558.

David, D. H., Gelberg, L., \& Suchman, N. E. (2012). Implications of homelessness for parenting young children: A preliminary review from a developmental attachment perspective. Infant Mental Health Journal, 33(1), 1-9. https://doi.org/10.1002/imhj.20333.

Davies, J. (2008). When battered women stay... advocacy beyond leaving. Retrieved from USA: http://www.bcsdv.org/resources/ BCS-Pub20.pdf

Davies, L., \& Krane, J. (2006). Collaborate with caution: Protecting children, helping mothers. Critical Social Policy, 26(2), 412-425. https://doi.org/10.1177/0261018306062592.

Elfer, P. (2012). Psychoanalytic methods of observation as a research tool for exploring young children's nursery experience. International Journal of Social Research Methodology, 15(3), 225-238. https:// doi.org/10.1080/13645579.2011.582295.

Featherstone, B., \& Fraser, C. (2012). Working with fathers around domestic violence: Contemporary debates. Child Abuse Review, 21(4), 255-263. https://doi.org/10.1002/car.2221.

Fonagy, P., Gergely, G., \& Target, M. (2007). The parent-infant dyad and the construction of the subjective self. Journal of Child Psychology and Psychiatry, 48(3-4), 288-328. https://doi.org/10. 1111/j.1469-7610.2007.01727.x

Gilbert, R., Widom, C. S., Browne, K., Fergusson, D., Webb, E., \& Janson, S. (2009). Burden and consequences of child maltreatment in high-income countries. The Lancet, 373(9657), 68-81. https:// doi.org/10.1016/S0140-6736(08)61706-7.

Groves, B. M. (2002). Children who see too much: Lessons from the child witness to violence project. Boston: Beacon Press.

Hall Gueldner, S., Britton, G. R., \& Terwilliger, S. (2012). Giving voice to vulnerable populations. In M. D. Chesnay \& B. A. Anderson (Eds.), Caring for the Vunerable (3rd ed., pp. 125-134). Burlington: Jones \& Barlett Learning.

Huntington, N., Buckner, J. C., \& Bassuk, E. L. (2008). Adaptation in homeless children: An empirical examination using cluster analysis. American Behavioral Scientist, 51(6), 737-755. https://doi.org/10. 1177/0002764207311985.

Huth-Bocks, A. C., Levendosky, A. A., Theran, S. A., \& Bogat, G. A. (2004). The impact of domestic violence on mothers' prenatal representations of their infants. Infant Mental Health Journal, 25(2), 79-98. https://doi.org/10.1002/imhj.10094.

Insetta, E. R., Akers, A. Y., Miller, E., Yonas, M. A., Burke, J. G., Hintz, L., \& Chang, J. C. (2015). Intimate partner violence victims as mothers: Their messages and strategies for communicating with children to break the cycle of violence. Journal of Interpersonal Violence, 30(4), 703-724. https://doi.org/10.1177/ 0886260514535264

James, J., \& Newbury, J. (2010). Infants, relational truama and homelessness. In T. Baradon (Ed.), Relational trauma in infancy. Great Britain: Routledge.

Jones, S., \& Bunston, W. (2012). The" original couple": Enabling mothers and infants to think about what destroys as well as engenders love, when there has been intimate partner violence. Couple and Family Psychoanalysis, 2(2), 215-232.

Keeshin, B., Oxman, A., Schindler, S., \& Campbell, K. (2015). A domestic violence shelter parent training program for mothers with young children. Journal of Family Violence, 30(4), 461-466. https://doi.org/10.1007/s10896-015-9698-6.

Krane, J., \& Davies, L. (2002). Sisterhood is not enough: The invisibility of mothering in shelter practice with battered women. Affilia, 17(2), 167-190. https://doi.org/10.1177/088610990201700203.

Krane, J., \& Davies, L. (2007). Mothering under difficult circumstances: Challenges to working with battered women. Affilia, 22(1), 23-38. https://doi.org/10.1177/0886109906295758.

Levendosky, A. A., Lannert, B., \& Yalch, M. (2012). The effects of intimate partner violence on women and child survivors: an attachment perspective. Psychodynamic Psychiatry, 40(3), 397-433.

Levendosky, A. A., Bogat, G. A., \& Martinez-Torteya, C. (2013). PTSD symptoms in young children exposed to intimate partner violence. Violence Against Women, 19(2), 187-201.

Lieberman, A. F., \& Van Horn, P. (2004). Don't Hit My Mommy: A manual for child-parent psychotherapy with young witnesses of family violence. Washington, DC: Zero To Three Press.

Lieberman, A. F., \& Van Horn, P. (2008). Psychotherapy with infants and young children: Repairing the effects of stress and trauma on early attachment. New York: Guilford Press.

Lieberman, A. F., Chu, A., Van Horn, P., \& Harris, W. W. (2011). Trauma in early childhood: Empirical evidence and clinical implications. Development and Psychopathology, 23(2), 397-410. https://doi.org/10.1017/S0954579411000137.

Lindsey, E. W. (1998). The impact of homelessness and shelter life on family relationships. Family Relations, 47(3), 243-252.

Mbilinyi, L., Edleson, J., Hagemeister, A., \& Beeman, S. (2007). What happens to children when their mothers are battered? Results from a four city anonymous telephone survey. Journal of Family Violence, 22(5), 309-317. https://doi.org/10.1007/s10896-007-9087-x.

McIntosh, J. (2002). Thought in the face of violence: A child's need. Child Abuse \& Neglect, 26(3), 229-241. https://doi.org/10.1016/ S0145-2134(01)00321-0.

McIntosh, J. (2003). Children living with domestic violence: Research foundations for early intervention. Journal of Family Studies, 9(2), 219-234. https://doi.org/10.5172/jfs.9.2.219.

Medico, D., \& Santiago-Delefosse, M. (2014). From reflexivity to resonances: Accounting for interpretation phenomena in qualitative research. Qualitative Research in Psychology, 11(4), 350-364. https:// doi.org/10.1080/14780887.2014.915367.

Meyer, S. (2012). Why women stay: A theoretical examination of rational choice and moral reasoning in the context of intimate partner violence. Australian \& New Zealand Journal of Criminology, 45(2), 179-193. https://doi.org/10.1177/0004865812443677.

O'Sullivan, N. (2019). Creating space to think and feel in child protection social work; a psychodynamic intervention. Journal of Social Work Practice, 33(1), 15-25. https://doi.org/10.1080/02650533.2018. 1460589 . 
Peled, E., \& Dekel, R. (2010). Excusable deficiency: Staff perceptions of mothering at shelters for abused women. Violence Against Women, 16(11), 1224-1241. https://doi.org/10.1177/1077801210386775.

Pinheiro, P. S. (2006). Secretary-General's study on violence against children: Promotion and protection of the rights of children. Retrieved from Geneva, Switzerland:

Pretorius, I.-M. (2004). The skin as a means of communicating the difficulties of separation-Individuation in toddlerhood. Infant Observation, 7(1), 68-88. https://doi.org/10.1080/ 13698030408401710.

Puckering, C., Connolly, B., Werner, C., Toms-Whittle, L., Thompson, L., Lennox, J., \& Minnis, H. (2011). Rebuilding relationships: A pilot study of the effectiveness of the mellow parenting programme for children with reactive attachment disorder. Clinical Child Psychology and Psychiatry, 16(1), 73-87. https://doi.org/10.1177/ 1359104510365195.

Rasool, S. (2015). Help-seeking after domestic violence: The critical role of children. Journal of Interpersonal Violence, 31, 1-26. https://doi. org/10.1177/0886260515569057.

Reddy, V., \& Trevarthen, C. (2004). What we learn about babies from engaging their emotions. Zero to Three, 24(3), 9-15.

Rhode, M. (2004). Infant observation as research: Cross-disciplinary links. Journal of Social Work Practice, 18(3), 283-298. https:// doi.org/10.1080/0265053042000314384.

Rustin, M. (1997). What do we see in the nursery? Infant observation as 'laboratory work.'. Infant Observation, 1(1), 93-110. https://doi. org/10.1080/13698039708400828.

Rustin, M. (2009). Esther Bick's legacy of infant observation at the Tavistock-Some reflections 60 years on. Infant Observation, 12(1), 29-41.

Samuelson, K. W., Krueger, C. E., \& Wilson, C. (2012). Relationships between maternal emotion regulation, parenting, and children's executive functioning in families exposed to intimate partner violence. Journal of Interpersonal Violence, 27(17), 3532-3550. https://doi. org/10.1177/0886260512445385.

Schechter, D. S., \& Willheim, E. (2009). The effects of violent experiences on infants and young children. In C. H. Z. Jr (Ed.), Handbook of infant mental health (pp. 197-213). New York: The Guilford Press.

Schechter, D. S., Moser, D. A., Wang, Z., Marsh, R., Hao, X., Duan, Y., et al. (2012). An fMRI study of the brain responses of traumatized mothers to viewing their toddlers during separation and play. Social Cognitive and Affective Neuroscience, 7(8), 969-979.

Schechter, D. S., Willheim, E., Suardi, F., Serpa, S., \& Rusconi. (2019). The effects of violent experiences on infants and young children. In C. H. Zeanah Jr. (Ed.), Handbook of infant mental health (4th ed., pp. 219-238). USA: The Guilford Press.

Schmidt Neven, R. (2007). Constructing Mental Health Problems: A critical inquiry into the views of professionals working with children, parents and families. $(\mathrm{PhD})$, Victoria University.

Secco, L., Letourneau, N., \& Collins, E. (2016). 'My eyes were open': Awakened maternal identity and leaving violent relationships for the infant/children. Journal of Family Violence, 31(5), 639-645. https:// doi.org/10.1007/s10896-016-9799-x.
Shinn, M. (2010). Homelessness, poverty, and social exclusion in the U.S. and Europe. European Journal on Homelessness, 4(1), 21-44.

Shinn, M., Schteingart, J. S., Williams, N. C., Carlin-Mathis, J., BialoKaragis, N., Becker-Klein, R., \& Weitzman, B. C. (2008). Longterm associations of homelessness with children's well-being. American Behavioral Scientist, 51(6), 789-809. https://doi.org/10. 1177/0002764207311988.

Silverman, D. (2013). Doing qualitative research: A practical handbook (4th ed.). London: SAGE.

Stern, D. N. (1985/2003). The interpersonal world of the infant: A view from psychoanalysis and developmental psychology. London: Karnac Books.

Stern, D. N. (2010). Forms of vitality: Exploring dynamic experience in psychology, the arts, psychotherapy, and development. New York: Oxford University Press.

Tailor, K., \& Letourneau, N. (2012). Infants exposed to intimate partner violence: Issues of gender and sex. Journal of Family Violence, 27(5), 477-488. https://doi.org/10.1007/s10896-012-9441-5.

Taylor, A. K., Gregory, A., Feder, G., \& Williamson, E. (2019). 'We're all wounded healers': A qualitative study to explore the well-being and needs of helpline workers supporting survivors of domestic violence and abuse. Health \& Social Care in the Community, 27(4), 856-862. https://doi.org/10.1111/hsc.12699.

Thiara, R. K., \& Humphreys, C. (2015). Absent presence: The ongoing impact of men's violence on the mother-child relationship. Child \& Family Social Work, 22, 1-9. https://doi.org/10.1111/cfs.12210.

Thompson, S., \& Phillips, D. (2007). Reaching and engaging hard-toreach populations with a high proportion of nonassociative members. Qualitative Health Research, 17(9), 1292-1303. https://doi. org/10.1177/1049732307307748.

Thomson Salo, F. (2007). Relating to the infant as subject in the context of family violence. In F. Thomson Salo \& C. Paul (Eds.), The baby as subject (2nd ed.). Victoria: Stonnington Press.

Thomson Salo, F., \& Campbell, P. (2007). Some principles of infantparent psychotherapy. In F. T. Salo \& C. Paul (Eds.), The baby as subject (2nd ed., pp. 247-259). Melbourne: Stonnington Press.

UN. (1989). Convention on the rights of the child. Retrieved from Geneva: UN General Assembly.

Van der Kolk, B. (2014). The body keeps the score: Brain, mind, and body in the healing of trauma. England: Penguin.

Van Manen, M. A. (2017). The first cry of the child. Qualitative Health Research, 27(7), 1069-1076. https://doi.org/10.1177/ 1049732316673342 .

Waddell, M. (2013). Infant observation in Britain: A Tavistock approach. Infant Observation, 16(1), 4-22. https://doi.org/10.1080/13698036. 2013.765659.

Winnicott. (1960). The theory of the parent-infant relationship. International Journal of Psychoanalysis, 41, 585-595.

Winnicott, D. W. (1968/1988). Babies and their mothers. London: Free Association Books.

Publisher's Note Springer Nature remains neutral with regard to jurisdictional claims in published maps and institutional affiliations. 